\title{
Nucleation and growth of new grains in recrystallized quartz vein: An example from banded iron formation in Iron Quadrangle, Brazil
}

\author{
Leonardo Lagoeiro*, Paola Barbosa \\ Universidade Federal de Ouro Preto, Departamento de Geologia, Ouro Preto, MG 35400-000, Brazil
}

\section{A R T I C L E I N F O}

\section{Article history:}

Received 28 August 2008

Received in revised form

8 March 2010

Accepted 12 March 2010

Available online 18 March 2010

\section{Kewords:}

Crystallographic orientation

Universal stage

Electron backscatter diffraction (EBSD)

Recrystallization

Quartz

\begin{abstract}
A B S T R A C T
Intracrystalline microcracks developed in quartz single crystals deformed in greenschist metamorphic conditions. A detailed study of samples collected in tabular to lens shape quartz vein was carried out to investigate how the microcracks initiated and how the microstructures evolved with the progressive deformation. A combination of light and EBSD (electron backscatter diffraction) techniques was used to analyze the microstructures and determine the crystallographic orientation of quartz grains. The crystallographic orientations of microcracks indicate that they might have initiated parallel to the direction of one of the rhombohedral planes of the host crystals. It is suggested that new grains nucleated by rotation of broken fragments from the host grains. $c$-axes the of host are distributed in a small-circle close to the foliation plane while the $c$-axes of the new grains in microcracks are more scattered when compared with the host orientations. New grains grew with their c-axes approximately perpendicular to the shortening direction.
\end{abstract}

(c) 2010 Published by Elsevier Ltd.

\section{Introduction}

Small new grains found in zones of localized deformation are thought to be produced by dynamic recrystallization. The strong crystallographic preferred orientation (CPO) and the microstructures of the dynamically recrystallized aggregates are taken as evidence for crystal-plastic origin of these zones. Dynamic recrystallization is considered a process that accompanies dislocation creep and involves the formation and migration of high angle grain boundaries, in response to deformation, in the same mineral (Vernon, 1981; Urai et al., 1986). Recrystallization does not produce new minerals during deformation, a process better referred to as neocrystallization (Urai et al., 1986). Models to describe dynamic recrystallization are based on two main processes: (1) subgrain rotation recrystallization (Urai et al., 1986; White, 1977) and (2) grain-boundary migration recrystallization (Urai et al., 1986; Gordon and Vandermeer, 1966).

Models based on dislocation glide have been used to explain the crystallographic preferred orientations (CPO) determined in quartz (Jessell, 1988; Jessell and Lister, 1990). Experimental studies reported CPOs in host grains not entirely recrystallized developed by mechanical reorientation as a result of intracrystalline slip

\footnotetext{
* Corresponding author. Tel.: +55 31 35591859; fax: +55 3135591606 .

E-mail address: lagoeiro@degeo.ufop.br (L. Lagoeiro).
}

(Gleason et al., 1993). Nonetheless most of the best CPOs in rocks were determined in recrystallized quartz grains.

However, investigation of dynamically recrystallized grains in both experimentally (den Brok, 1992; Vernooij et al., 2006) and naturally deformed aggregates (van Daalen et al., 1999; Bestmann and Prior, 2003) have shown that the misorientation between parent and recrystallized grains cannot be easily explained in terms of subgrain and grain boundary recrystallization. Therefore, other processes may exert an important control on the misorientation between host and recrystallized grains. Three models have been proposed to explain the large misorientation angle observed between host and recrystallized grains: (1) recrystallized grains once formed may be deformed by grain-boundary sliding assisted by diffusive mass transfer (Bestmann and Prior, 2003; Lagoeiro and Fueten, 2008); (2) new grains precipitated out of solution in voids and microcracks (den Brok and Spiers, 1991; Hippertt and EgydioSilva, 1996) and (3) new grains are fragments that were rotated and separated from the host grain during sliding (den Brok 1994; van Daalen et al., 1999; Vernooij, et al., 2006).

The samples studied in this paper have features similar to those predicted in those three models above. Intracrystalline microfractures developed in quartz single crystals found in tabular to lens shape quartz veins. However, microstructures and crystallographic orientations differ slightly from those described in the previous studies. In our studied quartz veins, we aim to understand how the intracrystalline microcracks nucleate and further evolve to an 
aggregate of recrystallized quartz grains. We also investigate in detail the role of dynamic recrystallization as well as of other processes during the progressive deformation in the microfracture zones, once these aggregates were deformed at relatively low temperature $\left(\sim 300{ }^{\circ} \mathrm{C}\right)$ with participation of aqueous fluid (Hippertt and Egydio-Silva, 1996; Lagoeiro, 1998).

\section{Geological setting and sample description}

The quartz vein studied in this paper came from banded iron formations from the Iron Quadrangle (IQ) in the Southeast of Brazil (Fig. 1). The IQ is an Archean/Proterozoic terrane located at the southern boundary of the São Francisco Craton (Almeida, 1977). The IQ comprises metavolcanic and metasedimentary sequences surrounded by gneissic-granitic-migmatitic domes (Alkmim and Marshak, 1998). The sequences are folded and a regional foliation $\left(S_{1} / S_{b}\right)$ developed parallel to the axial planes of the major synclines and anticlines. In the iron formation rocks the regional foliation $\left(S_{1}\right)$ is expressed as an alternately compositional banding $\left(S_{\mathrm{b}}\right)$ of quartz and iron oxides (magnetite and hematite) parallel to the $S_{1}$ foliation. Ductile shear zones developed mainly parallel to this compositional banding and are related to the flexural slip occurring during the folding process. The samples of quartz veins came from one of these shear zones located in the overturned limb of the Serra do Curral Syncline. It consists of a steeply SE-dipping isoclinal syncline trending NE-SW. The axial foliation/banding is moderately to steeply SE-dipping and the stretching lineation, associated with a top-to-the-SE sense of tectonic transport, trends NW-SE.

The mineral assemblage (Pires, 1995) and microstructures (Hippertt, 1994) found in metapelitic and quartizitc (quartz and sericite) country rocks indicate that the deformation occurred under greenschist facies conditions $\left(\sim 300-350^{\circ} \mathrm{C}\right)$ and involved a widespread participation of water-rich fluids (Herz, 1978). The long axes of the quartz and hematite grains define the down-dip lineation and were used to orient the samples in the field.

The analyzed quartz veins are embedded in a matrix of iron oxide (magnetite and hematite) and quartz. They are oriented parallel to the foliation/compositional banding. The compositional banding consists of an alternation of varied proportions of iron oxide and quartz layers. Most quartz veins are made of fragments of single crystals (host grains) of a few millimeters wide and several millimeters long (Fig. 2) connected by polycrystalline aggregates of granular quartz crystals (Lagoeiro and Fueten, 2008). Quartz host grains are elongated approximately parallel to the lineation direction. Some quartz veins are composed only by aggregates of granular quartz of lens shape and in this case they are described as pure quartz layers. In this study only quartz with both types of grains, i.e. single crystals and granular aggregates of quartz, was selected for microstructural and crystallographic preferred orientation (textural) analyzes. Although several vein samples have been sectioned for microscopic observations only three more representative examples (BIFQV01, BIFQV02 and BIFQV03) were taken for detailed microstructural and crystallographic orientation analyses.

\section{Methods}

All investigated samples (BIFQV01, BIFQV02 and BIFQV03) were cut perpendicular to the boundary quartz-iron oxide and parallel to the long axis of elongate quartz grains. These planes and directions were used to orient the samples. The $X$-axis was taken parallel to the maximum elongation of quartz grains, the $Z$-axis perpendicular to the interface quartz-iron oxide and the $Y$-axis perpendicular to

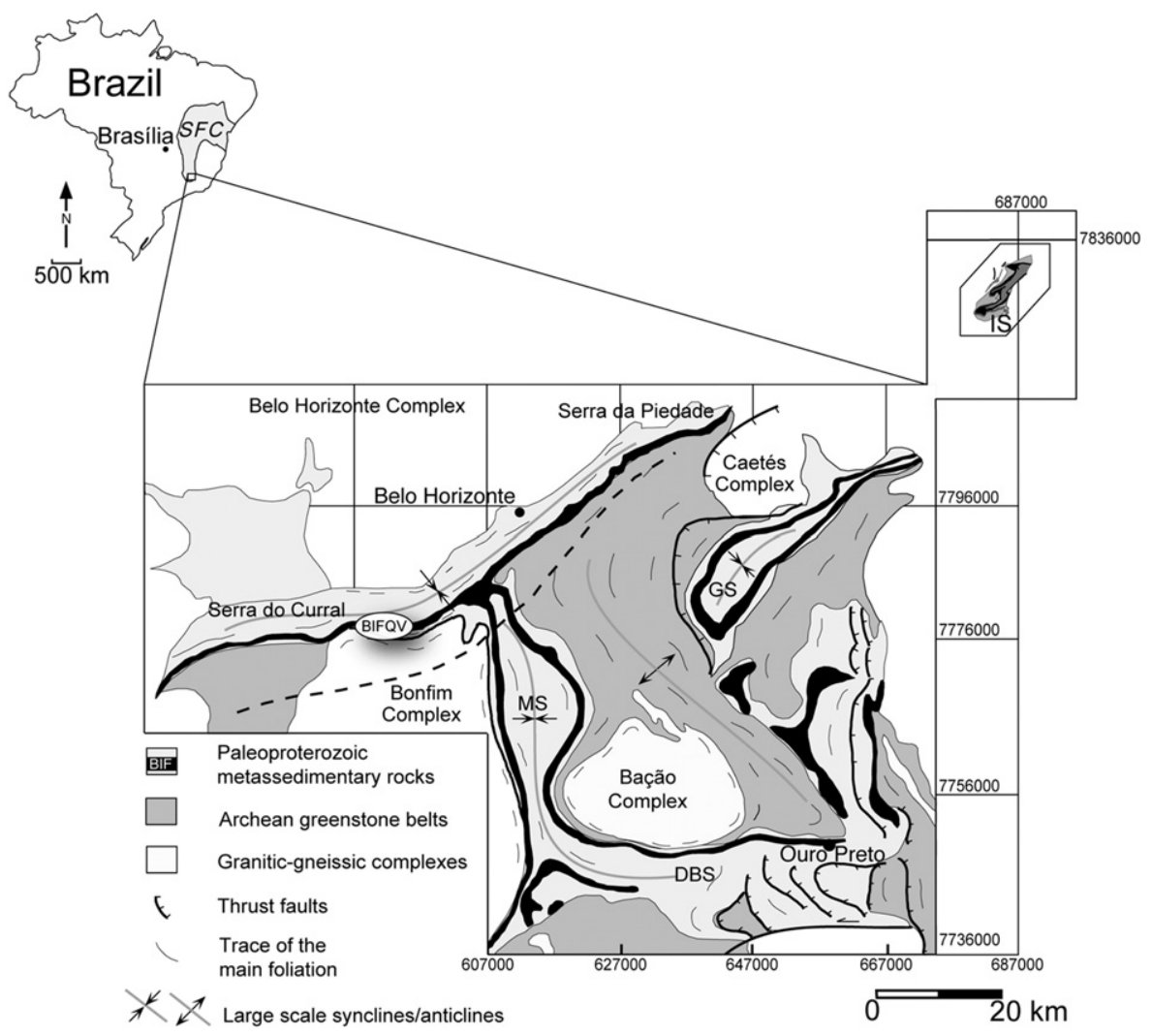

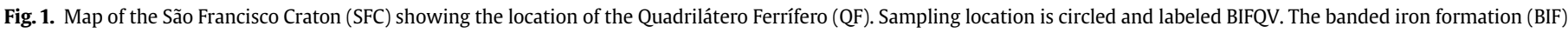
in the Quadrilátero Ferrífero geological map is painted in black (after Dorr, 1969 and Alkmim and Marshak, 1998). 

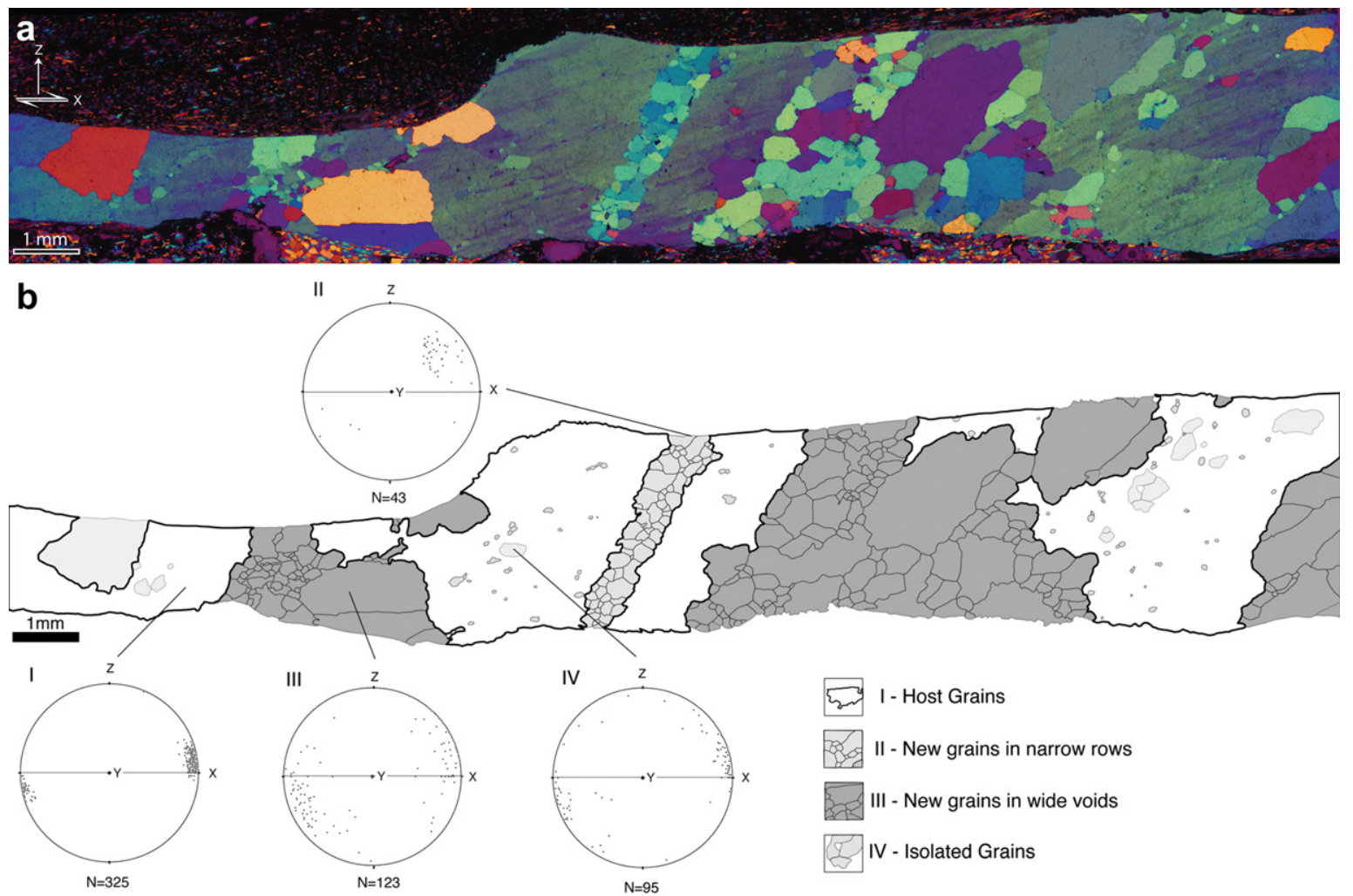



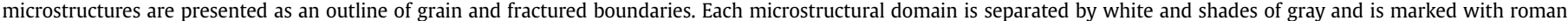

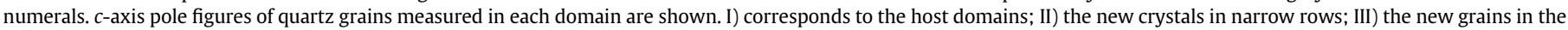
wide voids and IV) the isolated new grains.

the $X Z$ plane. Initially, a series of optical micrographs of the veins were taken with crossed polarizers and the lambda plate inserted $(\lambda=550 \mathrm{~nm})$ and assembled in a mosaic (Fig. 2a). Then grain boundaries were contoured manually and further digitalized (Fig. 2b). One representative mosaic of all analyzed veins (BIFQV01) is presented in Fig. 3. This figure also shows an outline of the microstructures from which the grain size, shape and axial ratios were measured using the Image SXM program (Barrett, 2005).

\subsection{Universal stage}

The $c$-axis of quartz grains were measured with the help of a universal stage (u-stage) mounted on an optical microscope. The microcrack surface orientations were also measured using a u-stage. A microcrack segment was brought to a vertical position with the ustage. In a vertical position the fracture trace was oriented parallel to the $\mathrm{N}-\mathrm{S}$ direction of the ocular cross wire. In that position the orientation of the pole to the fracture surface was measured. The optical axes of the host (the $c$-axes) as well as of the new quartz grains in both side of the fracture surface were determined in horizontal $\mathrm{E}-\mathrm{W}$ or in vertical orientation with respect to the microscope stage. In quartz only the $c$-axis orientation can be measured by the u-stage. Therefore, only the angle between the $c$-axis and the pole to the fracture boundary can be determined and it is not possible to determine unambiguously the crystallographic orientation of the fracture segment. Notwithstanding, in the trigonal symmetry of quartz crystals sets of crystallographic planes differing only in sign exhibit the same characteristic angle to the $c$-axis. Therefore it is reasonable to ascribe specific angles to specific sets of crystallographic planes. The subgrain-boundary orientations were obtained using the same procedure. This method has been applied to the determination of the crystallographic orientation of quartz-quartz interfaces by Kruhl and Paternell (2002). Although the u-stage serves as the only instrument to measure the spatial orientation of a small segment of the boundary and the $c$-axis at the same time with sufficient accuracy, the method has some limitations. The u-stage can be inclined up to $50^{\circ}$ and



Fig. 3. Microstructures of host grains (HG) in the quartz veins. Boundaries of elongate subgrains are parallels to the $c$-axis of the host crystals. 
therefore fracture surfaces dipping $0-50^{\circ}$ with respect to the thin section plane cannot be measured. This inability poses a bias in selecting the analyzed fracture surface segment population and might change the probability of occurrence of specific crystallographic planes. In general the effect of the limited inclination of the ustage on the frequency distribution of some crystallographic orientations can be avoided by measuring the fracture surface orientation in YZ sections. The cut-off effect on the u-stage measurements and its statistical significance will be verified below.

\subsection{Electron backscatter diffraction}

One sample (BIFQV03) was used for SEM electron backscatter diffraction (EBSD, e.g. Prior et al. 1999) analysis of the host and the new grains. The sample was sectioned using a precision saw and then diamond polished down to $0.25 \mu \mathrm{m}$. The final lapping procedure took about 8 hours in an immersion of colloidal silica $(20 \mathrm{~nm})$. The electron microscope was set to $20 \mathrm{KV}$. The sample surface was inclined to $70^{\circ}$ to the horizontal at a working distance of $33 \mathrm{~mm}$. A minimum deviation angle of $2^{\circ}$ was used for acquisition and of $<1^{\circ}$ for pole figure calculation. The EBSD patterns were collected automatically at $10 \mu \mathrm{m}$ intervals and processed using Channel 5 software package (HKL-Oxford). In the orientation map (Fig. 5a) the color of each pixel corresponds to the crystal direction parallel to the $X$-direction of the sample. In the pattern quality map gray shades are related to the band contrast of the EBSD pattern (Fig. 5b). The pattern quality or band contrast map reproduce surface damage, fracture and (sub)grain boundaries and provide an additional image of the microstructures. For that reason it is useful to verify the reliability of the orientation maps. The misorientation angle between adjacent points was determined by selecting the minimal angle of rotation necessary to bring one lattice into a coincidence to the other (Wheeler et al., 2001). The distributions of misorientation axes are presented in the sample and crystal reference frames for the host and new grain domains. The nearest neighbor misorientations are represented by their axes for small $\left(2-5^{\circ}\right)$ and large $\left(>10^{\circ}\right)$ misorientation angles.

\section{Results}

The quartz veins consist of large fragments of single crystals (millimeters in diameter) separated by aggregates of smaller quartz grains (Fig. 2 and 3). These grains occur along narrow rows (two or three grains wide) of slightly elongated crystals as well as larger grains filling wide gaps between fragments of single crystals that were broken off from the host grains.

\subsection{Microstructures and orientation data}

\subsubsection{Host grain}

Host grain fragments are highly deformed and contain several subgrain boundaries (misorientation angles up to $10^{\circ}$ ). On average, subgrains have dimensions of $300 \mu \mathrm{m}$ in length and $60 \mu \mathrm{m}$ in width. They are elongated at an angle of $\sim 15-25^{\circ}$ to the $X$-direction of the sample reference frame (Fig. 4a) and oriented approximately perpendicular to the $Z$-axis, suggestive of a plate-like shape of the subgrains (Fig. 4b).

The host grains show strong crystallographic preferred orientations (CPO). The CPOs of the host consist of a strong $c$-axis maximum at the periphery of the pole figure $\sim 15-25^{\circ}$ to the $X$ direction of the sample reference frame (Fig. 2, domain I and Fig. $5 \mathrm{a}-\mathrm{c}$ ). The $a$-axis maxima occupy a great circle that is slightly tilted with respect to the foliation plane ( $X Y$ plane of the sample). The poles to $\{10-10\}$ and $\{2-1-10\}$ show rather similar distribution patterns. The poles to rhomb $\{10-11\}$ and $\{01-11\}$ define three distinct maxima.

Subgrains and host crystals show gradual lattice bending. Figs. $6 a$ and $b$ show the distribution of misorientation axes with respect to the sample and the crystal reference frames. The misorientation axes for low angle misorientations $\left(2-10^{\circ}\right)$ and for high angle misorientations $\left(>10^{\circ}\right)$ are plotted separately. The misorientations within the host domains are mainly low angles. The misorientation axes cluster around the $X$-direction and roughly coincide with the preferred orientation of the host c-axes. Only few high angle boundary segments were observed within the host domains. They have similar axes as low angle boundary segments.

Blocks of single host crystals are separated by microcracks and voids with varied widths. Healed microfractures within the host grains are traced by very tiny fluid and solid (iron oxide) inclusions (Fig. 7a). The poles of the straight segments of fractured host crystals in the flanking host domains were plotted on the SE segment of the small-circle with an opening angle of $\sim 70^{\circ}$ and they make angles of $35-65^{\circ}$ with the $c$-axes of the host grains (Fig. $7 \mathrm{~b}$ and $\mathrm{c}$ ). These angles suggest that microcracks may have developed mainly parallel to the direction of one of the rhombohedral planes. The healed microcracks within the host grains have similar orientations. However, the preferred orientation of the poles to microcrack surfaces along the edge of the stereonet may reflect the restricted measurability of the u-stage. To evaluate the u-
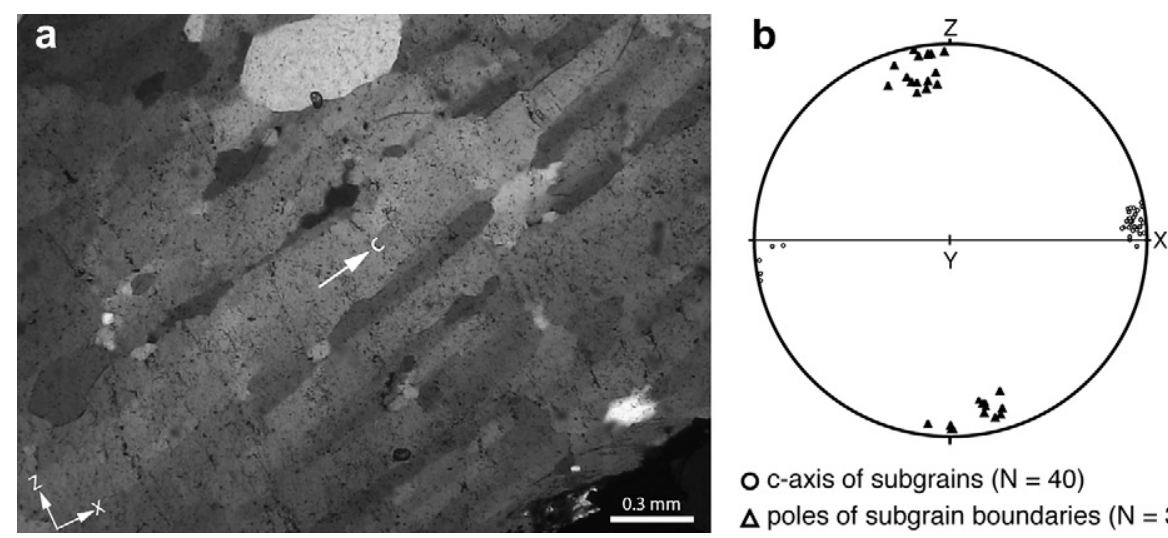

O c-axis of subgrains $(\mathrm{N}=40)$

$\Delta$ poles of subgrain boundaries $(N=30)$

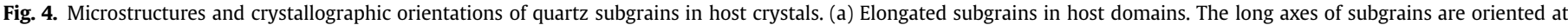


(equal area projection) in the lower hemisphere. The horizontal line (X-axis) is parallel to the foliation trace and the mineral lineation. 

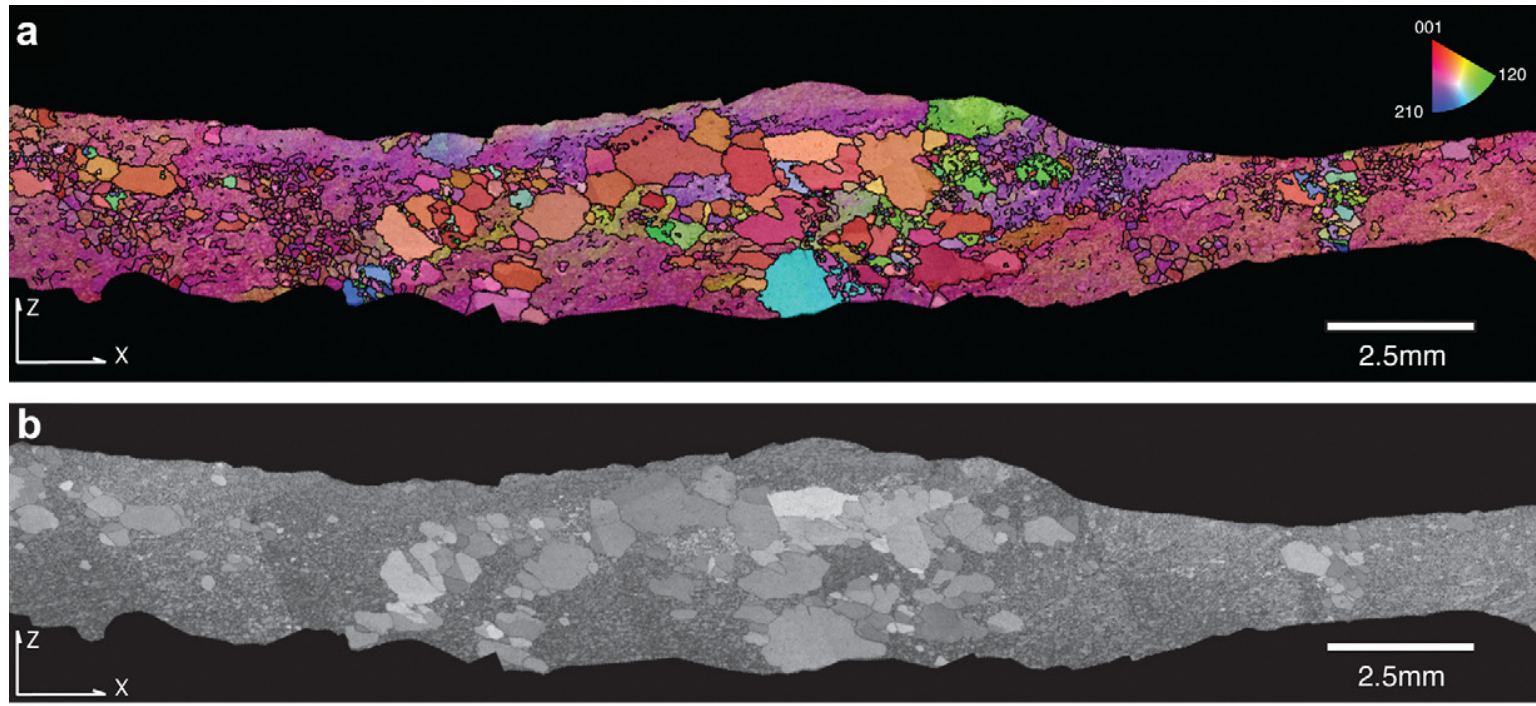

\section{C host grains}

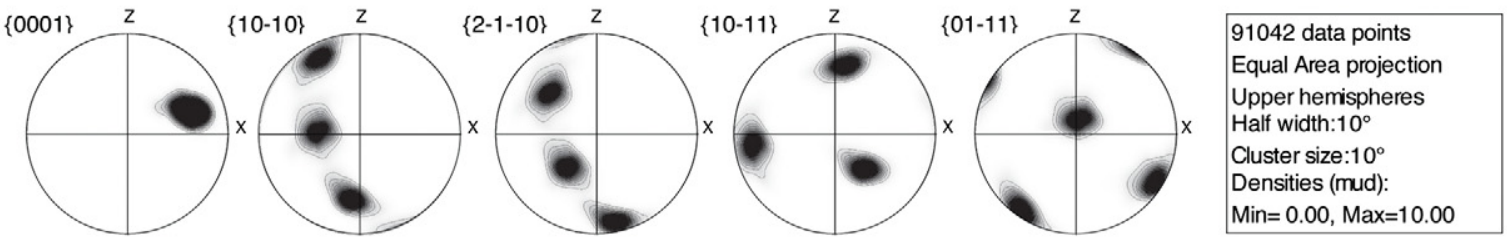

d new grains in narrow rows



3963 data points
Equal Area projection
Upper hemispheres
Half width: $10^{\circ}$
Cluster size: $10^{\circ}$
Densities (mud):
Min $=0.00$, Max $=10.00$

\section{e new grains in wide voids}
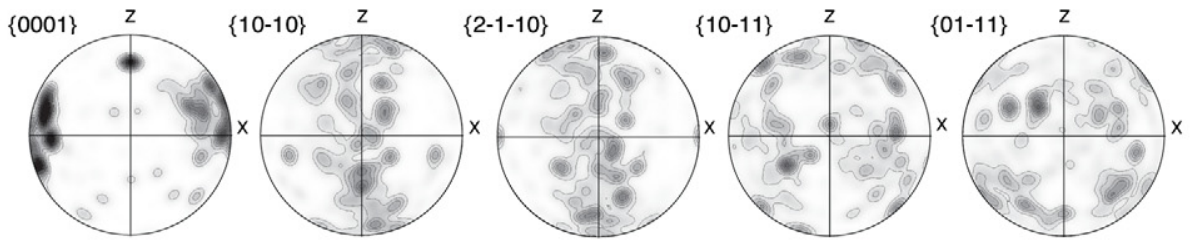

52462 data points
Equal Area projection
Upper hemispheres
Half width: $10^{\circ}$
Cluster size: $10^{\circ}$
Densities (mud):
Min $=0.00$, Max $=10.00$

\section{f isolated new grains}
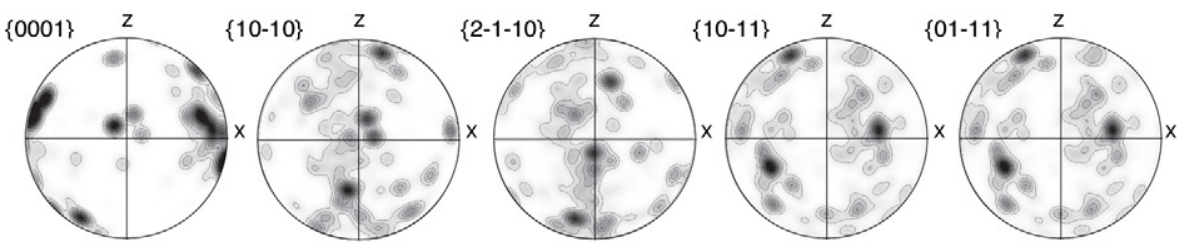

9448 data points
Equal Area projection
Upper hemispheres
Half width: $10^{\circ}$
Cluster size: $10^{\circ}$
Densities (mud):
Min $=0.00$, Max $=10.00$

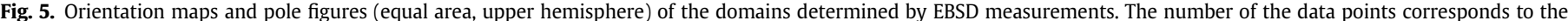

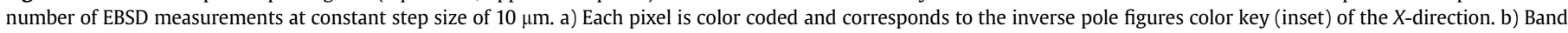

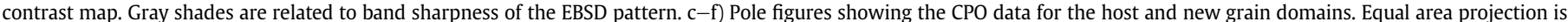

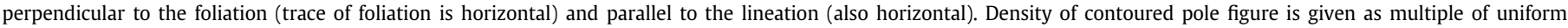
distribution (mud) of nonpolar data on an upper hemisphere. For each sample the $c(0001)$ axes and the poles to $\{10-10\},\{2-1-10\},\{10-11\},\{0-1-11\}$ are shown. 


\section{a host grains}
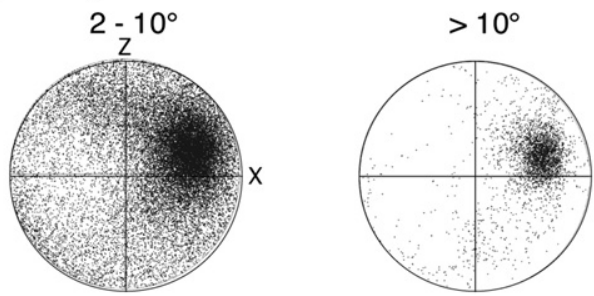

C new grains in narrow rows


e new grains in wide voids
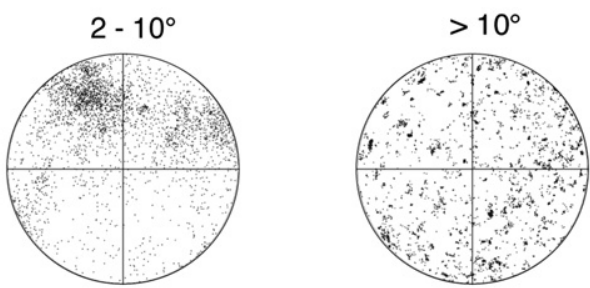

g isolated grains $2-10^{\circ}$
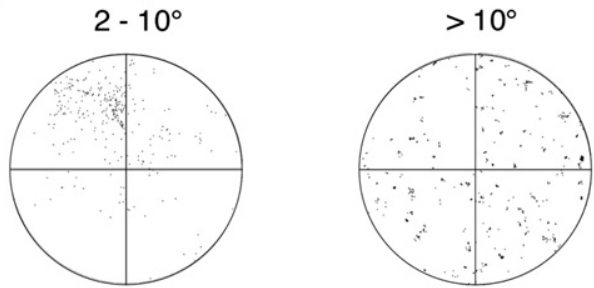

b host grains



$2-10^{\circ}$ $>10^{\circ}$


f new grains in wide voids
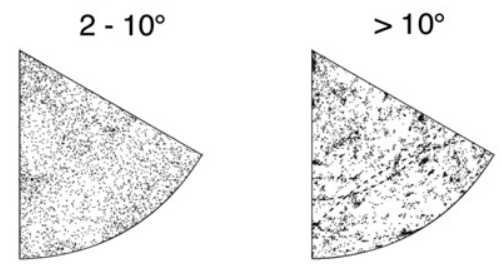

$\mathbf{h}$ isolated grains

$$
2-10^{\circ}
$$

$>10^{\circ}$


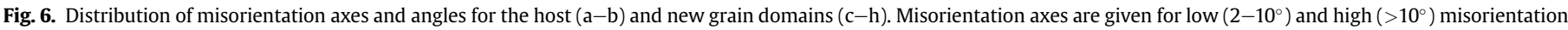
angles with respect to the sample and crystal reference frames (equal area, upper hemisphere projection).

stage constrains on the crystallographic preferred orientations of the microfracture boundaries, the microfracture orientations were also measured in sections perpendicular to the lineation $(Y Z$ section; Fig. 7d). It appeared that the inability of the u-stage to measure the shallowly oriented microfracture segments do not significantly change the probability of occurrence of any crystallographic plane (cf. Kuntcheva et al. 2006).

\subsubsection{New grains}

New grains within the microcracks are optically strain-free (Figs. 2 and 3). No undulatory extinction or subgrains are observed in the thin sections (Fig. 8a). The size of new grains varies (Fig. 8b) according to the microcrack or void width. In narrow rows (Fig. 3, domain II), there is only little variation in grain size (average size $150 \mu \mathrm{m}$ ), contrasting to the large size distribution in wide voids (20 $\mu \mathrm{m}$ to over $1 \mathrm{~mm}$ in the central part). However, in both cases, grain size and shape are dissimilar to the size and shape of subgrains. Although some new grains have straight boundaries with polygonal configuration, others tend to show less regular boundaries, with reentrant and rounded contours. The new grains are on average more or less equant in shape with long to short axis ratio around 1.3 (Fig. 8c). Slightly elongated grains can also be observed in these polycrystalline domains, particularly in those of widely spaced voids as shown in domain III of Fig. 2. Their long axes are oriented roughly perpendicular to the shortening direction.

The transition between the host and the new grains are sudden with differences in $c$-axis orientation between host and new grains larger than $20^{\circ}$ (Fig. 8d). In narrow microcracks, new grains have their $c$-axes distributed in a small circle with an open angle of $\sim 45^{\circ}$ (domain II in Figs. 3 and 5d). The $c$-axis orientations of the new grains spread away from the host $c$-axes. The poles to the prism and rhomb planes (Fig. 5d) show distribution patterns somewhat similar to those of the host grains. However the crystallographic orientations in these domains tend to be more dispersed and the strong maxima observed for the host crystals are not seen for the new grains in the narrow cracks. The distribution of the misorientation axes does not show any clear trend irrespective of the reference frame (Fig. $6 \mathrm{c}$ and d).

The crystallographic orientations of the new grains in the widely spaced voids are still more scattered than those of the host and the new grains in the narrower cracks (domain III in Fig. 3). The pole figures (Fig. 5e) illustrate a dispersion of the $c$-axis orientations of the new grains away from the host $c$-axes. The poles to prism and rhomb planes show a scattered distribution that resembles those of the host crystals but it lacks the clear maxima observed in the latter. The only clear trend for the distribution of the misorientation 





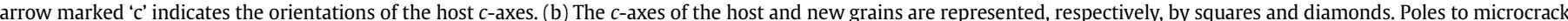

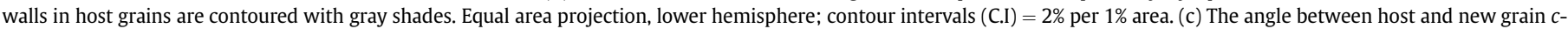

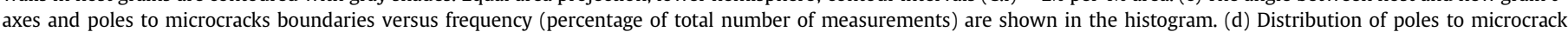


down-dipping parallel to the lineation (in the center of the projection). Equal area projection, lower hemisphere; contour interval (C.I) $=2 \%$ per $1 \%$ area.

axes in the new grains in the wide voids occurs for misorientation angles up to $10^{\circ}$ (Fig. 6e and f). Two clusters of misorientation axes apart approximately at $90^{\circ}$ to each other are observed for this interval with respect to the sample reference frame. In the crystal reference frame the misorientation axes have a slight preference for the $c$-axes for misorientation angles up to $10^{\circ}$. For misorientation intervals larger than that there is no clear preference of the misorientation axes for any direction in the sample or in the crystal reference frame.

New grains also occur as isolated pockets within the host domains (Fig. 9a). Similar to the new grains in the microcracks, isolated grains also have uniform intracrystalline orientation and thus are strain-free. Their sizes vary in a wide range, from few micrometers to a millimeter in diameter (Fig. 9b). They are slightly elongated with their long axes perpendicular to the incremental shortening direction, i.e. at $40-45^{\circ}$ to the quartz vein boundary (Fig. 9c). Again, the isolated grain size and shape are inconsistent with those of subgrains in the host domains. The transition from the host to isolated new grains, although less abrupt than that shown by the new grains in the microcracks, also have a wide range in misorientation angles (Fig. 9d). The crystallographic orientations of the isolated crystals also show a wide range of distribution (Fig. 5f). The $c$-axes show a maximum concentration close to the lineation. The poles to prism and rhomb planes show distributions somewhat similar to those of the new grains in narrow and wide domains. However the crystallographic orientations of the isolated crystals spread more widely and that clear crystallographic orientation patterns observed for the host grains are no longer discernible for the isolated grains within the host. The misorientation axes are also distributed in a scattered way regardless of the reference frame (Fig. $6 \mathrm{~g}$ and $\mathrm{h}$ ). Only for the misorientation intervals up to $10^{\circ}$ there is a slight preference for the misorientation axes as the Z-direction of the sample reference frame. In the crystal reference frame the misorientation axes do not show any preference for any crystallographic direction.

\section{Discussions}

In the classical model for dynamically recrystallized grains by subgrain rotation, subgrains are expected to gradually increase the misorientation to the parent grain. Eventually, subgrain walls become high angle boundaries $\left(>10^{\circ}\right)$ and then become new grains. The misorientation between parent and new grains is expected to be low $\left(<20^{\circ}\right)$. The new grains should also have sizes compatible with those of subgrains. However, in our samples there is a discrepancy between size of subgrains and the new grains. The new grains are smaller or larger than the subgrains in the host grains, but rarely of the same size. The crystallographic orientation of new grains shows a progressive misorientation away from the flanking host crystal. The misorientation angles between host and new grains can be larger than $50^{\circ}$. Therefore alternative models should be considered to explain these large misorientations between host and new grains.

Two models seem to be adequate to explain the observed microstructures and the crystallographic orientations, namely the microfracture model and the precipitation model of new grain 

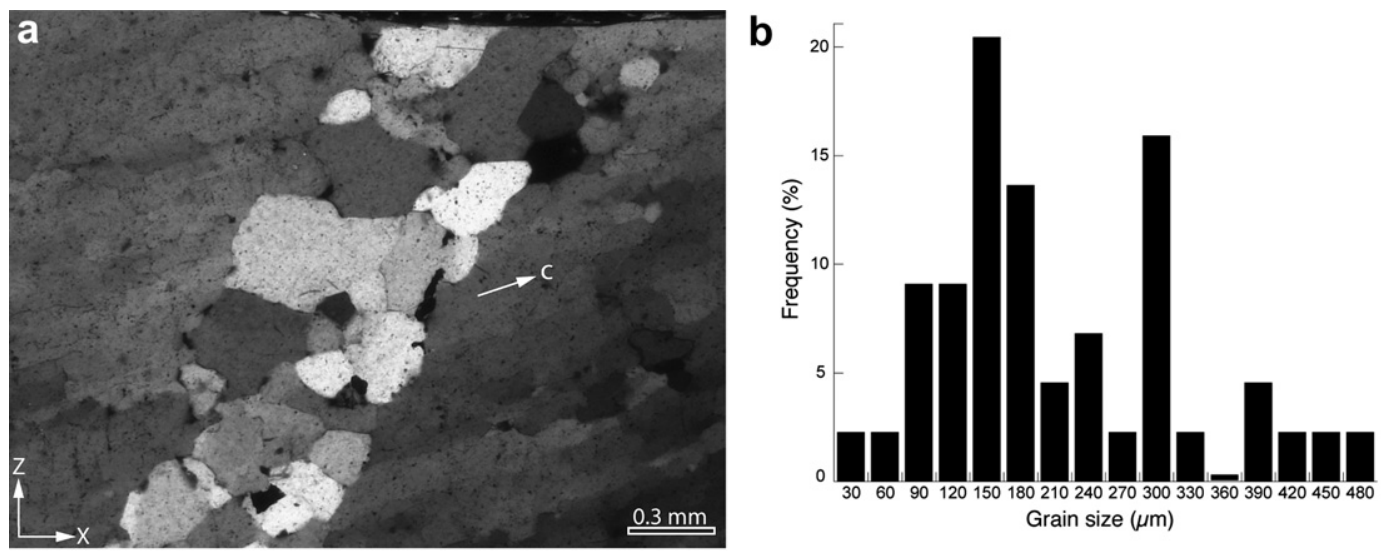

C

d
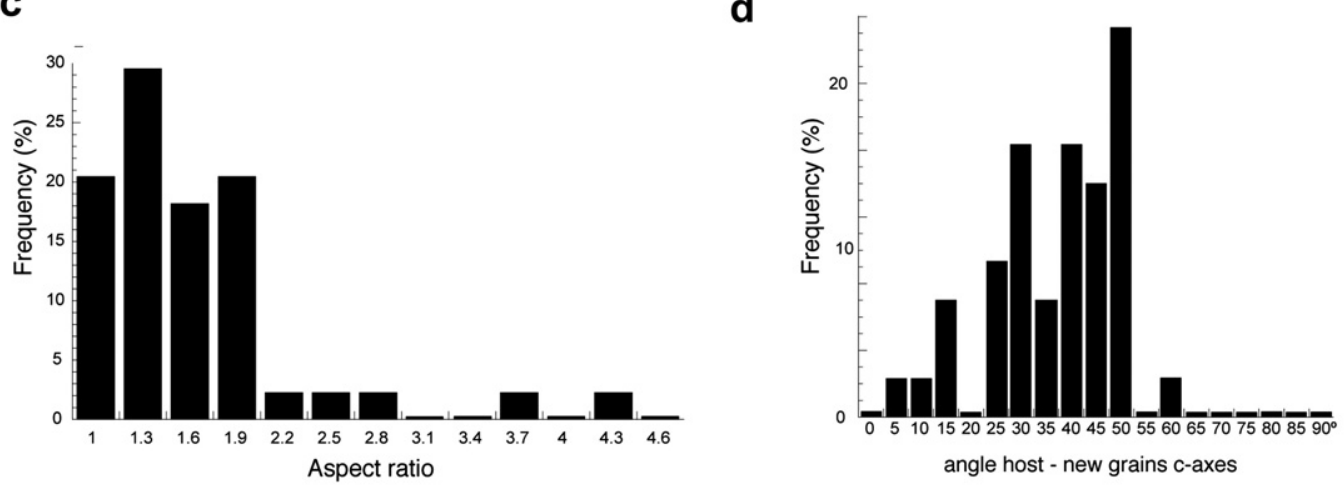



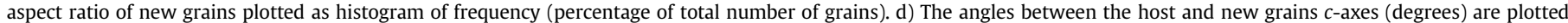
against the frequency (percentage of the total number of grains measured).

formation. In the microfracture model (Sander, 1911; Griggs and Bell, 1938; den Brok, 1992, 1994; van Daalen et al., 1999; Vernooij et al., 2006) microcracks initiate and fragments subsequently rotate. In our samples fracturing occurred preferentially along the trace of one of the rhombohedral planes in the deformed quartz veins. Host crystals were not oriented well for basal slip, since their $c$-axes are at low angle to the boundary between the quartz vein and the matrix. Thus slip initiated along the basal planes leading to the formation of elongated subgrains parallel to $c$-axes. Because the crystal orientation prevents any further slip on basal and other conventional slip systems, microcracks may start to develop at $40-50^{\circ}$ to the host $c$-axes, possibly enhanced by aqueous solution. Some cracks might heal after little rotation remaining visible as trails of fluid and iron oxide inclusions. Further movement along cracks may lead to the formation of fragments that are progressively rotated. According to this model, new grains are considered as broken off fragments that heal after rotation. The progressive rotational displacement, probably facilitated by the aqueous fluids, increases the misorientation between the host and the fractured fragments. Large displacement leads to a large lattice misfit and to the formation of new grains. The new grains seem to have grown parallel to the direction of maximum extension. This can be deduced from the slightly elongated shape $(\sim 1.3)$ of the new grains in these domains. This orientation is ideal for glide on basal plane in case of the deformation by dislocation creep at these low temperatures (Schmid and Casey, 1986). Thus the recrystallized grains might have deformed further by glide nevertheless they have an optically uniform orientation. The presence of fluid and solid inclusions along healed microfractures and fragments strengthen the interpretation of the deformation by microfracturing. This model of recrystallization by microfracturing was proposed to explain the microstructures and crystallographic orientation in experimental study on quartz (den Brok, 1992, 1994; Vernooij et al. 2006), as well as in naturally deformed quartz fibers (van Daalen et al., 1999).

The disparity in grain size observed in the wide voids, particularly in the central regions, is hardly explained by these mechanisms of subgrain formation and growth. One possible explanation for that might be the normal growth of those grains by static recrystallization during a period of annealing after ceasing of deformation. However, static recrystallization would also have wiped out the optical deformation microstructures observed in the host crystals. But this appears not to be the case in our studied samples. Moreover, the fact that the host grains are deformed and the recrystallized quartz crystals are not can also be explained by partial recrystallization no matter whether dynamic (syn-kinematic) or static (post-kinematic).

An alternative explanation might be the precipitation of new grains out of solution in cracks and voids. In fact, the grain size and orientation of grains close to the flanking host crystal in more widely spaced voids are similar to the grains in narrowly spaced ones. Those cracks might have initiated as a narrow one by a mechanism of breaking off and rotation of fragments that would explain the similarities between microstructures of the two sets of grains. With the progressive deformation, the width of narrow microcracks increases, which makes them hardly be recognized as a microcrack, and the new grains precipitate in the space between breaking apart fragments. The crystallographic orientation of the new grains in the wider voids are scattered further away from the host orientation than the crystallographic orientation of the new grains in the narrower microcracks. The development of new grains in isolated pockets appears to be incompatible with the 

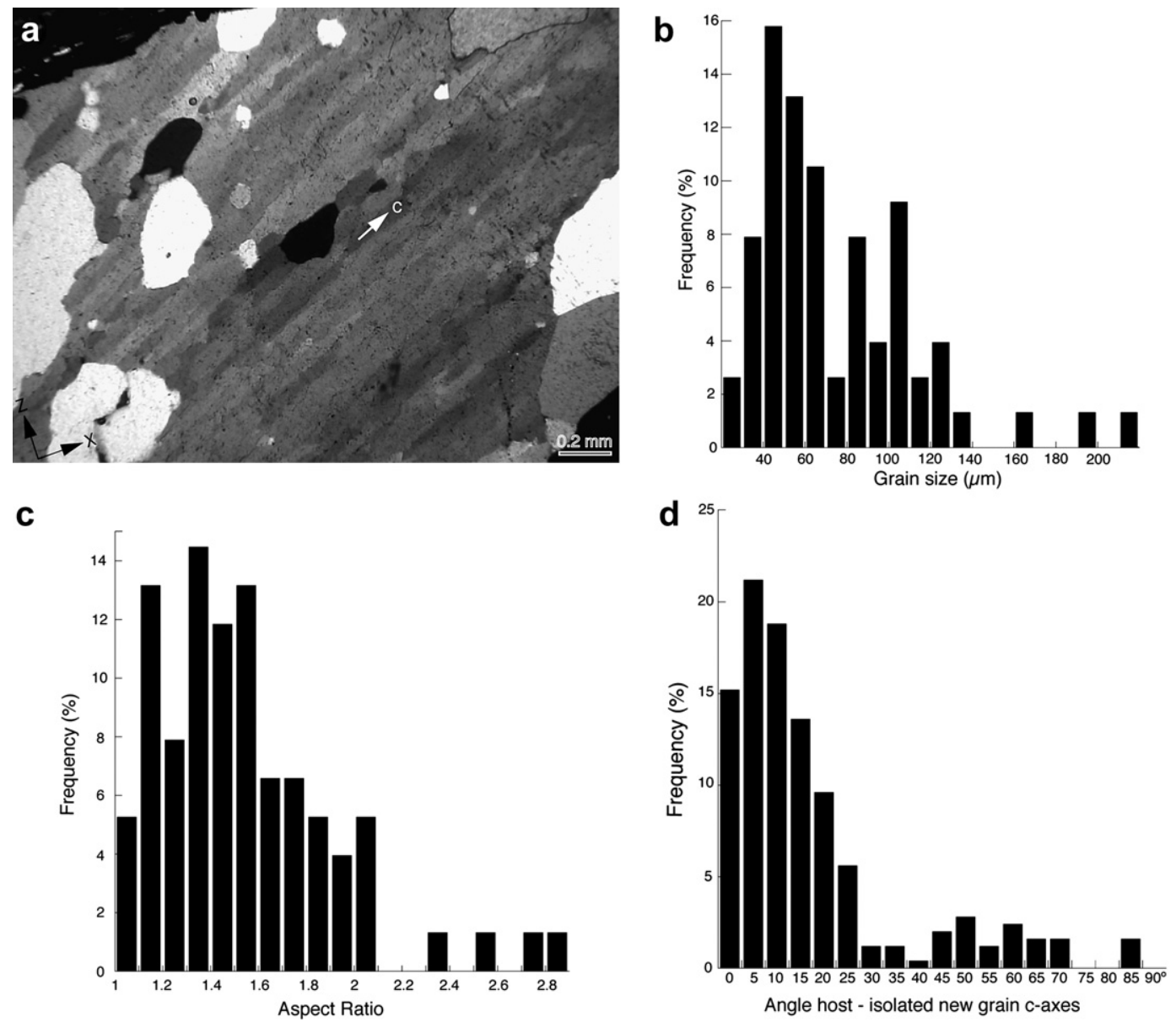

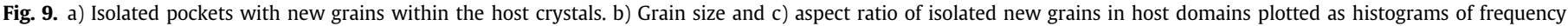
(percentage of total number of measurements). d) Histogram showing the angles between $c$-axes of host and isolated new grains.

microfracturing model. The geometry of these grains and the difference in crystallographic orientation to the host crystals suggest that these new grains might have nucleated with crystallographic orientations which are not necessarily dependant on the crystallographic orientation of host crystal. Therefore, we suggest that these new grains might have grown by precipitation from solution in small voids or microcracks within the host crystals, similarly to the dissolution/precipitation experiments (den Brok and Spiers, 1991) and observations of naturally deformed quartzites (Hippertt and Egydio-Silva, 1996). The slightly elongated shape $(\sim 1.3)$ of the new grains suggests that subsequent growth must have taken place by fluid assisted grain-boundary migration (Drury and Urai, 1990; Mancktelow and Pennacchioni 2004) relatively fast perpendicular to the direction of maximum shortening.

\section{Conclusions}

Our microstructural and crystallographic data allow us to draw the following conclusions:

(1) Microfractures developed preferentially at $35-65^{\circ}$ to the $c$-axis of the host crystals. After little rotation, these microcracks might have healed and they can be now traced in the host crystals as trails of fluid and solid inclusions. Further microcracking led to the development of planar microfractures parallel to the trace of one of the rhombohedral planes in the flanking host domains.
(2) New grains may have developed along initial microcracks by fracturing and progressive rotation of fragments. Larger grains, found in the center of wide microcracks, having contrasting crystallographic orientation to the host and as well to the new grain in the narrow planar fractures, might have been developed by precipitation out of solution and subsequent fluid assist growth.

(3) Host grains have their $c$-axes oriented at low angle to the $X$-axis of the pole figure, an orientation of hard slip on basal planes. In contrast, the new grains are developed with their $c$-axis parallel to the incremental stretching direction. That corresponds to an orientation of easy-slip on basal planes for new developed grains. New grains with that orientation grew faster and further deformed by glide which explains the slight elongation of new grains perpendicular to the incremental shortening direction.

(4) New isolated grains might have been precipitated and grown out of solution in similar way of that proposed for the development of new grains in the central region of wide cracks and voids.

\section{Acknowledgements}

We thank to Luiz Morales and Issamu Endo for stimulating discussions and suggestions. L. Lagoeiro is grateful for financial support by CNPq project 200968/2005-0 and FAPEMIG CRA APQ3166-5.02/07. 


\section{References}

Alkmim, F.F., Marshak, S., 1998. Transamazonian orogeny in the southern São Francisco Craton region, Minas Gerais, Brazil: evidence for Paleoproterozoic collision and collapse in the Quadrilátero Ferrífero. Precambrian Research 90, 29-58.

Almeida, F.F.M., 1977. O Cráton de São Francisco. Revista Brasileira de Geociências 7, $349-364$.

Barrett, S., 2005. Image SXM. Surface Science Research Centre.

Bestmann, M., Prior, D.J., 2003. Intragranular dynamic recrystallization in naturally deformed calcite marble: diffusion accommodated grain boundary sliding as a result of subgrain rotation recrystallization. Journal of Structural Geology 25, 1597-1613.

den Brok, B., 1992. An experimental investigation into the effect of water on the ductile behaviour of quartz rocks. Geologica Ultraiectina 95, 178.

den Brok, S.W.J., 1994. Development of crystal plastic like deformation microstructures in quartz by micro-fracturing and solution/precipitation creep. Göttinger Arbeiten Zur Geologie und Paläontologie Sb1, 37-38.

den Brok, S.W.J., Spiers, C.J., 1991. Experimental evidence for water weakening of quartzite by microcracking plus solution-precipitation creep. Journal of the Geological Society 148, 541-548.

Dorr II, J.V.N., 1969. Physiographic, Stratigraphic and Structural Development of the Quadrilátero Ferrıífero, Minas Gerais, Brazil. In: United States Geological Survey Prof. Paper 641-A. United States Geological Survey, pp. 1-110.

Drury, M.R., Urai, J.L., 1990. Deformation-related recrystallization processes. Tectonophysics $172(3-4), 235-253$.

Gleason, G.C., Tullis, J., Heidelbach, F., 1993. The role of dynamic recrystallization in the development of lattice preferred orientations in experimentally deformed quartz aggregates. Journal of Structural Geology 15, 1145-1168.

Gordon, P., Vandermeer, R.A., 1966. Grain boundary migration. In: Margolin, H. (Ed.), Recrystallization, Grain Growth and Textures. American Society for Metals, pp. 205-266.

Griggs, D.T., Bell, J.F., 1938. Experiments bearing on the orientation of quartz in deformed rocks. Geological Society of America Bulletin 49, 1723-1746.

Herz, N., 1978. Metamorphic Rocks of the Quadrilátero Ferrífero, Minas Gerais, Brazil. In: United States Geological Survey Professional Paper 641-C.

Hippertt, J.F., 1994. Microstructures and c-axis fabrics indicative of quartz dissolution in sheared quartzites and phyllonites. Tectonophysics 229, 141-163.

Hippertt, J., Egydio-Silva, M., 1996. New polygonal grains formed by dissolutionredeposition in mylonitic quartzite. Journal of Structural Geology 18, 1345-1352.

Jessell, M.W., 1988. Simulation of fabric development in recrystallized aggregates. 2. Example model runs. Journal of Structural Geology 10, 779-793.

Jessell, M.W., Lister, G.S., 1990. A simulation of the temperature dependence of quartz fabrics. In: Knipe, R.J., Rutter, E.H. (Eds.), Deformation Mechanisms,
Rheology and Tectonics, 54. Geological Society Special Publication, pp 353-362.

Kruhl, J.H., Peternell, M., 2002. The equilibration of high-angle grain boundaries in dynamically recrystallized quartz: the effect of crystallography and temperature. Journal of Structural Geology 24, 1125-1137.

Kuntcheva, B., Kruhl, J.H., Kunze, K., 2006. Crystallographic orientations of highangle grain boundaries in dynamically recrystallized quartz: first results. Tectonophysics $421,331-346$.

Lagoeiro, L., 1998. Transformation of magnetite to hematite and its influence on the dissolution of iron oxide minerals. Journal of Metamorphic Geology 16, 415-423.

Lagoeiro, L., Fueten, F., 2008. Fluid-assisted grain boundary sliding in beddingparallel quartz veins deformed under greenschist metamophic grade. Tectonophysics 446, 42-50.

Mancktelow, N.S., Pennacchioni, G., 2004. The influence of grain boundary fluids on the microstructure of quartz-feldspar mylonites. Journal of Structural Geology 26 (1), 47-69.

Pires, F.R.M., 1995. Textural and mineralogical variations during metamorphism of the Proterozoic Itabira Iron Formation in the Quadrilátero Ferrífero, Minas Gerais, Brazil. Anais da Academia Brasileira de Ciências 67 (1), 77-105.

Prior, D.J., Boyle, A.P., Brenker, F., Cheadle, M.C., Day, A., Lopez, G., Peruzzo, L., Potts, G.J., Reddy, S., Spiess, R., Timms, N.E., Trimby, P., Wheeler, J., Zetterstrom, L., 1999. The application of electron backscatter diffraction and orientation contrast imaging in the SEM to textural problems in rocks. American Mineralogist 84 (11-12), 1741-1759.

Sander, B., 1911. Ueber zusammenhänge zwischen Teilbewegung und Gefüge in Gesteinen. Tschermaks Mineralogische Petrografische Mitteilungen 30 281-314.

Schmid, S., Casey, M., 1986. Complete fabric analysis of some commonly observed quartz c-axis patterns. In: Hobbs, B.E., Heard, H.C. (Eds.), The Paterson Volume Geophysical Monograph, 36, pp. 263-286.

Urai, J.L., Means, W.D., Lister, G.S., 1986. Dynamic recrystallization of minerals. AGU Geophysical Monograph 36, 161-199.

van Daalen, M., Heilbronner, R., Kunze, K., 1999. Orientation analysis of localized shear deformation in quartz fibres at the Brittle-Ductile transition. Tectonophysics 303, 83-107.

Vernon, R.H., 1981. Optical microstructure of partially recrystallized calcite in some naturally deformed marbles. Tectonophysics 78, 601-612.

Vernooij, M.G.C., den Brok, B., Kunze, K., 2006. Development of crystallographic preferred orientations by nucleation and growth of new grains in experimentally deformed quartz single crystals. Tectonophysics 427, 35-53.

Wheeler, J., Prior, D.J., Jiang, Z., Spiess, R., Trimby, P.W., 2001. The petrological significance of misorientations between grains. Contributions to Mineralogy and Petrology 141 (1), 109-124.

White, S., 1977. Geological significance of recovery and recrystallization processes in quartz. Tectonophysics 39 (1-3), 143-170. 